\title{
BUDIDAYA LELE SEBAGAI BENTUK PENUJANG SWASEMBADA PANGAN BAGI MASYARAKAT DESA
}

\author{
Ena Marlina ${ }^{1}$, Nuro Qolbi Aghitsnillah' ${ }^{2}$, Nasarudin Aruhi ${ }^{3}$, Nur Muhammad Rosyid2, \\ Lulut Ernin Maharani ${ }^{3}$, Farni Mudakir ${ }^{3}$, Eka Wahyu Sri Wilujeng' ${ }^{2}$, Alfiah Ekariani ${ }^{2}$, \\ Khovadli Ocvando ${ }^{2}$, Firman Hidayat ${ }^{4}$, Nanda Ayu Pawestri ${ }^{2}$, Faisholul Umam Al \\ Farrosi $^{3}$ \\ ${ }^{1}$ Fakultas Teknik, Universitas Islam Malang \\ ${ }^{2}$ Fakultas Agama Islam, Universitas Islam Malang \\ ${ }^{3}$ Fakultas Keguruan dan Ilmu Pendidikan, Universitas Islam Malang \\ ${ }^{4}$ Fakultas Pertanian, Universitas Islam Malang \\ Korespondensi email: ena.marlina@unisma.ac.id
}

\begin{abstract}
ABSTRAK
Program kerja ini bertujuan untuk mengembangkan perekonomian masyarakat desa. Melihat dari keadaan warga desa, Tim KKN membuat program kerja yang berhubungan untuk pengembangan perekonomian desa Wonoagung, selain itu program kerja ini sebagai bentuk kreatifitas mahasiswa. Budidaya ikan lele merupakan suatu usaha yang menjanjikan untuk di geluti waktu sekarang, kebutuhan akan ikan yang tinggi di pasaran, pasar ikan lele yang stabil membuat peternakan budidaya ikan lele di minati. Ikan lele yang mudah di kembangkan merupakan salah satu faktor pendukung untuk kemajuan budidaya ikan lele, dan tingkat ketahanan ikan lele terhadap perubahan cuaca yang baik mendukung berkembang cepatnya dan kemudahan peternak untuk menjadikan budidaya ikan lele pilihan yang tepat untuk usaha. Penelitian ini bertujuan untuk melakukan study kelayakan usaha terhadap usaha terhadap pembesaran ikan lele peternakan di Wonoagung yang di tinjau dari aspek aspek yang terkait dengan study kelayakan. Study kelayakan ini diharapkan untuk dapat mengetahui market pasar yang ada, dan kendala apa saja yang mungkin terjadi dalam proses mendirikan jenis usaha olahan ikan lele tersebut. Mengenai program pemasaran Tim menggunakan metode pemasaran berupa penawaran terhadap rumah makan, bekerja sama dengan pengepul dan di pasarkan melalui media sosial.
\end{abstract}

Kata Kunci: budidaya lele; management pemasaran; peningkatan perekonomian.

\section{PENDAHULUAN}

Dengan kondisi desa yang seperti tertinggal, desa yang dapat dijadikan sebagai modal pembangunan ekonomi, menjadi terhambat. Salah satu cara untuk meningkatkan atau menggali potensi ekonomi desa agar tidak tertinggal, adalah dengan melakukan pembangunan desa (Andini et al., 2015) (Trisnawati et al., 2018). Dengan adanya pembangunan desa, peningkatan ekonomi penduduk desa khususnya di desa tertinggal akan dapat dilakukan sehingga menjadi desa yang tidak tertinggal. Kondisi seperti ini memunculkan sebuah cara atau metode baru dalam hal membangun ekonomi (Ali et al., 2018).

Salah satu alternatif dalam pengembangan perekonomian desa adalah budidaya ikan lele. Lele merupakan salah satu jenis ikan air tawar yang sudah di budidayakan secara 
komersial terutama di pulau jawa (Pratama et al., 2016) (Dinasari Retnaningtyas, 2019). Budidaya lele berkembang pesat karena permintaaan pasar yang tinggi, budidaya yang relatif mudah di pahami masyarakat pemasaran yang relatif mudah serta modal usaha yang di butuhkan relatif rendah (Dwiyanto \& Jemadi, 2014). Lele di Wonoagung merupakan lele variant jumbo dengan pertumbuhan yang relatif baik, sehingga dapat di panen dengan lele berkembang pesat karena permintaaan pasar yang tinggi, budidaya yang relatif mudah di pahami masyarakat pemasaran yang relatif mudah serta modal usaha yang di butuhkan relatif rendah. Lele di Wonoagung merupakan lele variant jumbo dengan pertumbuhan yang relatif baik, sehingga dapat di panen dengan mudah (Muhammad \& Andriyanto, 2013).

Budidaya lele diterapkan pada masyarakat untuk memberikan inspirasi menciptakan lapangan kerja baru. Hasil dari panen ternak lele diharapkan dapat digunakan untuk menambah pendapatan masyarakat wonoagung dan sebagai bentuk latihan berwirausaha. Selain itu ternak lele ini memiliki keunggulan tersendiri dan sekaligus dapat meningkatkan dan mengembangkan keterampilan beternak khususnya ternak lele (Hidayat, 2017) (Susan \& Sophia, 2016).

Efisiensi dan efektifitas usaha pembesaran lele perlu dipelajari dengan seksama untuk menunjang keberhasilan budidayanya. Interaksi sesama pembudidaya lele sangat penting untuk menunjang keberhasilan pembesaran dan pemasaran lele yang dapat di lakukan dengan cara saling bertukar informasi tentang benih yang baik pakan bermutu dan pemasarannya. Lele dengan jenis jumbo ini bisa di panen dengan ukuran $18 \mathrm{~cm}$ di setiap ekornya dengan waktu budidaya 22 bulan lamanya. Strategi yang tepat dalam persiapan kolam pemeliharaan benih, pengisian air, management pasar, management mutu air, management panen dan pemasaran budidaya lele (Rabilla et al., 2018) (Hidayat, 2017).

\section{METODE}

Metodologi pelaksanaan ini mahasiswa bekerja sama dengan warga desa dari hal yang paling dasar mengenai apa yang sangat perlu di kembangkan, dengan adanya usulan dari warga berupa budidaya kolam lele mahasiswa mencoba mencari peternak lele yang di katakan sudah berpengalaman guna dijadikan patokan berjalannya program kerja tersebut.

\section{Tahap Program Kerja KKN}

Para Tim menyusun program kerja mengenai waktu yang di gunakan untuk melaksanakan program kerja. Waktu melakukan program kerja menyesuaikan dengan waktu masyarakat setempat. Program kerja menyusun estimasi modal yang di siapkan untuk melakukan program kerja tersebut, hingga menyusun rencana mengenai strategi pemasaran hasil dari ternak ikan lele.

2. Kegiatan Pendampingan

Dalam hal pendampingan para tim melakakukan bimbangan kepada karangtaruna untuk mendapatkan pengarahan mengenai pembudidayaan lele di desa Wonoagung kec Tirtoyudo, selain itu para team menyediakan web untuk sarana penjualan bibit lele untuk memudahkan kegiatan tersebut.

3. Evaluasi Progam

Evaluasi progam dilakukan secara berkala di setiap satu minggu sekali. Setiap minggu Evaluasi dilakukan oleh para team dengan dosen pembimbing, dengan adanya evaluasi ini dapat membantu program yg dikerjakan dapat terarah dengan benar,di minggu terakhir Evaluasi dilakukan bersama dengan dosen pembimbing dan ketua karang taruna desa Wonoagung kec Tirtoyudo. 
Pelaksanaan kegiatan dilaksanakan di suatu tempat yang representatif dimana pelaksanaannya dilakukan oleh seluruh warga pelaku usaha dibidangpeternakan lele yangmenjadi mitraprogram KKN PPM. Untuk mengefektifkan kegitan tersebut, metode yang digunakan metode praktis sesuai kebutuhan warga yang berupa metode praktik. Adapun pelatihan yang di berikan di antaranya pemasangan terpal untuk kolam, jumlah bibit dan takaran pakan lele.

Tim melaksanaka bimbingan langsung di lapangan atau tempat budidaya lele dan sekaligus melakukan evaluasi terhadap hasil pelatihan aspek-aspek dari aktivitas budidaya lele. Tim KKN menggunakan pemasaran berupa Web. Menegement pemasaran adalah merupakan kegiatan yang di koordinasikan dan dikelola dengan baik. Definisi pemasaran sendiri menurut Kolter yang di kutip Swashta dan Hani Handoko adalah sebagai berikut "management" pemasaran adalah penganalisaan perencanaan dan pengawasa program program yang bertujuan menimbulkan pertukaran dengan pasar yang di tuju dengan maksud untuk mencapai tujuan dari sebuah usaha.

Pendekatan pendampingan ini memfasilitasi pembuatan web sebagai sarana promosi lele. Dalam hal pemasaran teknik yang digunakan berupa media social berhubungan keadaan zaman sekarang, semakin berkembangnya teknologi untukpemasaran akan sangat membantu bagi para pengusaha untuk mengembangkan usahanya. Budidaya lele ini adalah sebagai salah satu kegiatan alternatif untuk meningkatakan pendapatan masyarakat dan pengetahuan masyarakat tentang budidaya ikan, khususnya budidaya ikan lele dikolam terpal, "dalam pelaksanaan kegiatan budidaya ikan lele ini dilakukan beberapa tahap kegiatan. Pertama diawali dengan kelompok masyarakat budidaya perikanan dan kegiatan monitoring kegiatan ini akan membantu dalam meningkatan pendapatan rumah tangga masing-masing masyarakat, kegiatan budidayaikan lele ini berlangsung selama 1 bulan sampai masa panen, pertumbuhan selanjutnya pembudidaya diharapkan dapat mengembangkan usaha budidaya ikan lele dikolam terpal, sumber air yang diigunakan, pada penebaran benih ikan lele,teknik pemberian pakan, pemantauan terhadap kualitas air dan penumbuhan ikan lele serta pemasaran ikan lele pasca panen agar tidak mengalami kesulitan dalam pemasaran ikan. Kegiatan budidaya ikan lele ini berlangsung selama kurang lebih 2 bulan sampai masa panen pertama.

\section{HASIL DAN PEMBAHASAN}

Kegiatan KKN yang utama adalah yang berkaitan mencari solusi terhadap kendalakendala yang dihadapi masyarakat terkait masalah ekonomi (Arifin \& Ariyanto, 2018). Potensi warga desa mengenai pengelolahan lahan pertanian sudah sangat berkembang sehingga mahasiswa berinovasi menciptakan kreativitas berbentuk budidaya ikan lele sebagai swasembada pangan. Dari hasil analisis kelompok 45 selama 1 bulan mengenai program kerja ini menghasilkan hal-hal sebagai berikut:

1. Terhadap permasalahan petani ikan lele mahasiswa mengajak masyarakat untuk mendampingi program kerja budidaya ikan lele. Pembukaan lahan yang bertempat di lahan balaidesa yang kosong yang dilakukan mahasiswa sebagai bentuk pemanfaatan lahan. Kelompok KKN bersama dengan organisasi karang taruna desa Wonoagung melakukan penyuluhan terhadap lapangan yang akan digunakan untuk budidaya lele. Kelompok KKN mensurvei kepada beberapa warga masyarakat yang memiliki peternakan ikan lele untuk memastikan bagaimana cara untuk mengembangkan budidaya lele agar berkembang dengan baik, kemudian mencari bibit ikan lele yang berkualitas baik dan bagus untuk di budidayakan. 


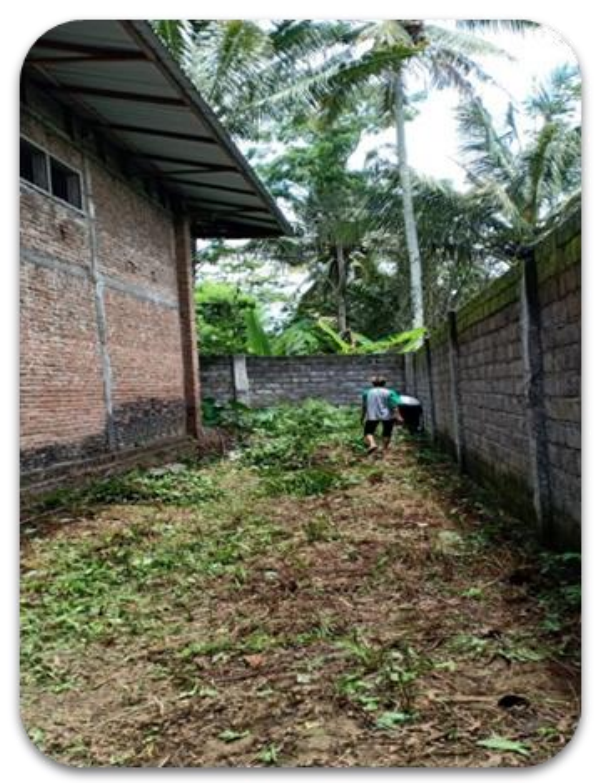

Gambar 1. Tim melakukan survey lokasi (dok. KKN Kel. 45)

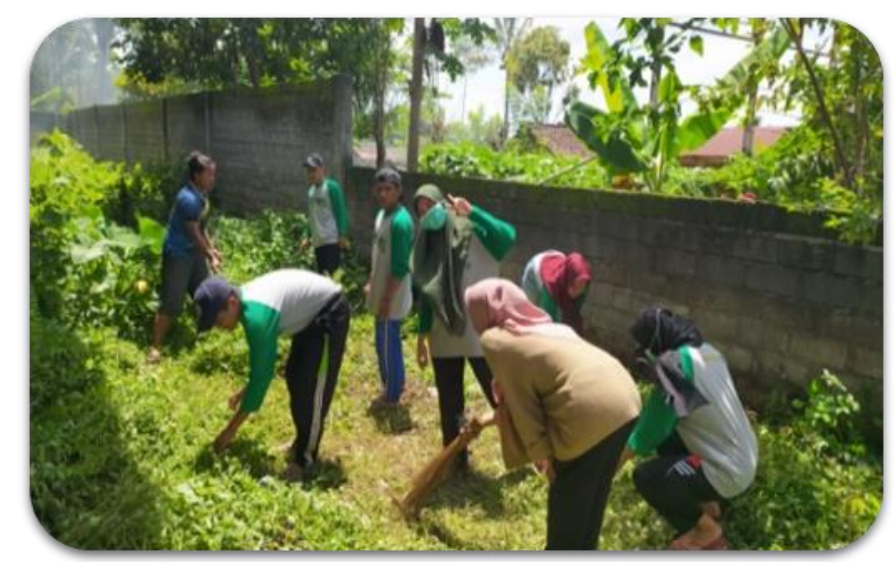

Gambar 2. Pembersihan lokasi yang akan dijadikan ternak lele (dok. KKN Kel. 45)

2. berkaitan dengan pembuatan kolam TIM KKN kami menggunakan kolam berjenis endapan atau yang tidak mengalir dan berbahan dasar terpal, Tim kkn memilih bahan dasar terpal karena harga terjangkau dan mudah untuk di pasang an di dapatkan sehingga dapat mengefisiensikan dana dan waktu.Selain itu kolam berbahan dasar terpal akan sangat memudahkan bagi para petani baru dan calon pengusaha baru sebab bahan terpal sangat mudah di temukan di pasaran.Tim kami membuat kolam dengan ukuran 2x1 meter dengan kedalaman sekitar kurang lebih $50 \mathrm{~cm}$. 


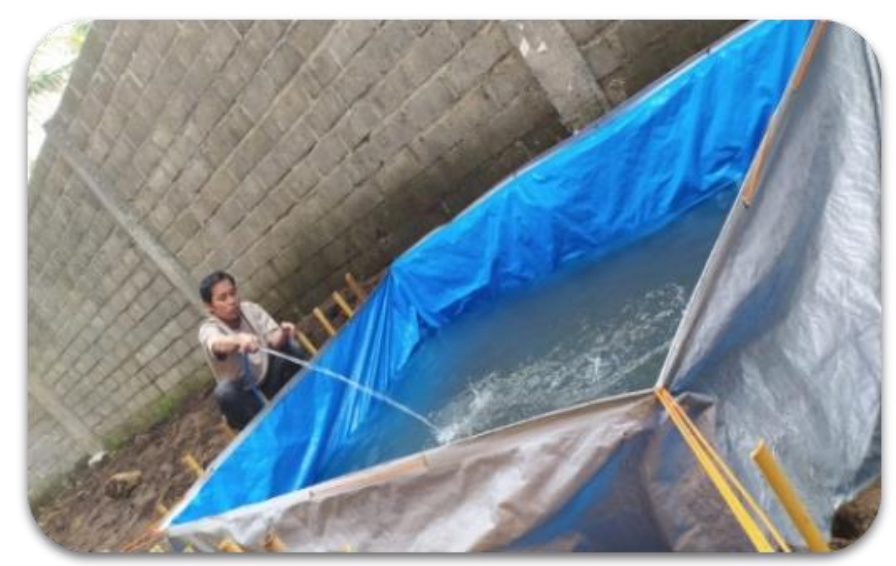

Gambar 3. Pembuatan kolam (dok. KKN Kel. 45)

3. Tim KKN memilih makanan untuk bibit lele dengan menggunakan pelet yang berukuran kecil dan menggunakan daun pepaya sebagai suplemen tamban Untuk cadangan makanan.

\section{KESIMPULAN}

Kuliah Kerja Nyata pembelajaran dan pengabdian masyarakat yang di laksanakan di desa Wonoagung Kecamatan Tirtoyudo Kabupaten Malang memfokuskan di bidang swasembada pangan di sektor perikanan yang ditujukan untuk meningkatkan perekonomian di desa tersebut. Dalam Kuliah Kerja Nyata pembelajaran dan pengabdian masyarakat yang di lakukan selama ini menggunakan metode praktis sesuai kebutuhan. Tujuan dari proker budidaya lele ini diharapkan akan memberikan motivasi kepada masyarakat selain itu untuk menunjang perekonomian masyarakat desa Wonoagung agar lebih maju dalam bidang ekonomi, sehingga desa Wonoagung memiliki wajah yang bagus di depan desa lainnya. Tim KKN kami menyerahkan hasil program kerja kami berupa 1 buah kolam yang berukuran 2x1 meter dan berisikan 250 bibit lele yang berjenis lele jumbo kepada karangtaruna desa tersebut guna di lanjutkan pembudidayaannya.

Pada Kuliah Kerja Nyata pembelajaran dan pengabdian masyarakat ini dapat di berikan saran saran sebagai berikut:

1. Perlu adanya pendampingan dari warga setempat agar kegiatan KKN PPM ini terus berjalan dengan lancar serta mengawal kegiatan perekonomian di masyarakat Wonoagung Kecamatan Tirtoyudo Kabupaten Malang.

2. Hasil kegiatan KKN PPM yang telah dilakukan terutama pengembangan swasembada pangan yang dilakukan di desa Wonoagung dapat di tindaklanjuti untuk mencapai tujuan yang di inginkan agar semua terlaksana tanpa adanya hambatan.

Dengan menindaklanjuti kegiatan ini, swasembada pangan harus dapat dikelola dengan sebaik mungkin oleh pengelola untuk kesejahteraan warga kedepannya, yang juga dapat meningkatkan taraf perekonomian desa Wonoagung.

\section{DAFTAR RUJUKAN}

Ali, U., Sumartono, \& Humaidah, N. (2018). IbM Kelompok Bisnis Peternakan Kambing Dan Domba Sebagai Hewan Qurban Dan Aqiqohan Di Karangbesuki, Sukun, Malang. Jurnal Inovasi Hasil Pengabdian Masyarakat (JIPEMAS), 1(2), 105-118. https://doi.org/10.33474/jipemas.v1i2.1515

Andini, U. H., Soeaidy, M. S., \& Hayat, A. (2015). Pemberdayaan Ekonomi Masyarakat Dari Desa Tertinggal Menuju Desa Tidak Tertinggal (Studi Di Desa Muktiharjo Kecamatan Margorejo Kabupaten Pati). Jurnal Administrasi Publik Mahasiswa Universitas 
Brawijaya,

2(12),

7-11. http://administrasipublik.studentjournal.ub.ac.id/index.php/jap/article/view/737

Arifin, M., \& Ariyanto. (2018). Desa Penghasil Kopi Untuk Meningkatkan Ekonomi Masyarakat Di Desa Damarwulan Kecamatan Keling Kabupaten Jepara. Jurnal Pengabdian Masyarakat Universitas Merdeka Malang, 3(1), 19-31. https://doi.org/10.26905/abdimas.v3i1.2247

Dinasari Retnaningtyas, I. (2019). Mengembangkan Budidaya Ternak Kelinci Guna Mewujudkan Desa Sejahtera Mandiri. Jurnal Pembelajaran Pemberdayaan Masyarakat (JP2M), 1(1), 6-11. https://doi.org/10.33474/jp2m.v1i1.4993

Dwiyanto, B. S., \& Jemadi. (2014). Wirausaha Kelompok Usaha Budidaya Pembesaran Lele. Jurnal Maksipreneur: Manajemen, Koperasi, Dan Entrepreneurship, 4(1), 4-21. https://doi.org/10.30588/jmp.v4i1.92

Hidayat, D. (2017). Pelatihan Kewirausahaan Budi Daya Ikan Lele Dumbo Untuk Pemberdayaan Pemuda Di Desa Kemiri Kecamatan Jayakerta Kabupaten Karawang. Jurnal Pendidikan Luar Sekolah, 1(1), 121-133.

Muhammad, W. N., \& Andriyanto, S. (2013). Manajemen Budidaya Ikan Lele Dumbo (Clarias gariepinus) di Kampung Lele, Kabupaten Boyolali, Jawa Tengah. Media Akuakultur, 8(1), 63-71. https://doi.org/10.15578/ma.8.1.2013.63-71

Pratama, F. A., Afiati, N., \& Djunaedi, A. (2016). Kondisi Kualitas Air Kolam Budidaya Dengan Penggunaan Probiotik dan Tanpa Probiotik Terhadap Pertumbuhan Ikan Lele Sangkuriang (Clarias sp) di Cirebon, Jawa Barat. Management of Aquatic $\begin{array}{llll}\text { Resources Journal (MAQUARES), } & \text { 5(1), }\end{array}$ https://ejournal3.undip.ac.id/index.php/maquares/article/view/10666

Rabilla, R. R., Satria, A., \& Yuliati, L. N. (2018). Strategi Pemasaran Lele Sangkuriang Organik Surya Kencana Farm Kota Bogor. MANAJEMEN IKM: Jurnal Manajemen Pengembangan Industri Kecil Menengah, 13(2), 137-142. https://doi.org/10.29244/mikm.13.2.137-142

Susan, \& Sophia, A. (2016). Pemberdayaan Masyarakat pada Kelompok Ternak Lele "Pangeran Jalon" di Desa Losarang, Indramayu (Community Development of Catfish Breeder Group "Pangeran Jalon" in Losarang Village, Indramayu). Jurnal CARE: Jurnal Resolusi Konflik, CSR, Dan Pemberdayaan, 1(1), 50-56. https://journal.ipb.ac.id/index.php/jurnalcare/article/view/15296

Trisnawati, A. E., Wahyono, H., \& Wardoyo, C. (2018). Pengembangan Desa Wisata dan Pemberdayaan Masyarakat Berbasis Potensi Lokal. Jurnal Pendidikan: Teori, Penelitian, Dan Pengembangan, 3(1), 29-33. https://doi.org/10.17977/JPTPP.V3I1.10356 